\title{
disputed by geophysicists
}

Los Angeles

US geophysicists made angry accusations last week that the US government is "lying" over estimated yields of Soviet underground nuclear tests. Allan Lindh of the US Geological Survey said at a symposium on treaty verification organized by the American Association for the Advancement of Science (AAAS) that geophysicists agree there is no evidence that the Soviet Union has cheated on the Yield Threshold Test Ban Treaty (YTTBT), which places an upper limit of 150 kilotons on weapons tests. The Department of Defense (DoD) was accused of hiding the evidence from citizens behind a "veil of secrecy".

The treaty verification symposium was one of the more heated sessions at this year's AAAS meeting, which included discussions on several aspects of arms control. Sally Horn of DoD repeated President Reagan's charge that the Soviet Union has probably exceeded the 150-kiloton limit in the YTTBT, which went into effect in 1976. Other speakers, notably Colin Gray of the National Institute of Public Policy, argued that because the Soviets have cheated on "most if not all" arms treaties (except the Nuclear Non-proliferation Treaty), such treaties have been "harmful or irrelevant".

Although much of the information needed to judge Soviet compliance with arms treaties is subject to security classification, analyses of seismic records are published in the open literature, and have been the subject of long-running arguments. The dispute centres on the method used to estimate explosive yields from seismic data, and in particular the bias parameter incorporated to take account of the local geology of the Soviet test site at Semipalatinsk.

Yield estimates are derived from body $\mathrm{P}$ waves at a frequency of about $1 \mathrm{~Hz}$. The relationship between the magnitude of an event judged from P-wave amplitude and explosive yield has been thoroughly investigated at the Nevada Test Site in the southwestern United States. According to Jack Evernden of the US Geological Survey, confirmed data published more than 10 years ago (based on comparisons with other types of seismic waves) indicate that for the Semipalantinsk test site a value of 0.4 should be subtracted from magni tudes to estimate explosive yield. That judgement has recently been confirmed by, among others, the Air Force Technical Applications Center in Florida, which has a primary responsibility for yield estimates. Present US government estimates, however, use a bias value of only 0.2 , resulting in yield estimates that are twice as high, as with the 0.4 value. Evernden says the decision to use a bias of 0.2 was "obscure", and claims there is unanimity among geophysicists that the higher value is correct. When the higher value is used, yield estimates converge on the 150-kiloton legal limit.

The DoD representative at the symposium was unable to shed any light on the matter. She professed unfamiliarity with the detailed arguments but admitted there was a "debate" on the question.

Seismic verification would be a crucial factor in any comprehensive test ban that might be negotiated in future; negotiations for such a ban were suspended in 1980 . Evernden, who used to work for DoD, publicly rebutted a paper published in Science in January this year by Willard Hannon of Lawrence Livermore Laboratory, which questioned whether a politically plausible detection network could detect most low-yield explosions. In Evernden's view, almost all test explosions above 1 kiloton (the limit of military value) can now be distinguished from earthquakes by a simple network of non-array detection stations. Others at the conference argued, however, that the lack of progress towards a more comprehensive test ban resulted from a lack of political will rather than for technical reasons.

Tim Beardsley

\section{US research restrictions}

\section{Pentagon prefers export control}

\section{Los Angeles}

THE US Department of Defense (DoD) has told the research community that it will in future make routine use of export regulations to restrict access of foreign nationals to scientific data which, while not classified, might be of military significance. As a result, many scientific and technical conference organizers will be obliged to put sensitive material in special "export-controlled sessions" restricted to US nationals and to foreign nationals only if validated by their embassies. Participants in such sessions must undertake to keep the restricted material confidential.

The new policy was spelled out at a meeting of the American Association for the Advancement of Science by Dr Sumner Benson, substituting for Richard Perle, Assistant Secretary for Defense for international security policy. In the past, some technical societies have voluntarily restricted access to conferences for fear of violating arms traffic regulations: the new policy, by giving control to DoD, will make such voluntary censorship unnecessary.

Export controls will be used only for scientific data that are not considered "fundamental". According to a DoD policy instituted last year by Richard DeLauer, then Under-Secretary of Defense for research and engineering, "fundamental" research on university campuses is controlled only by use of security classification.

The new policy outlined by Benson would implement authority in the 1984 DoD Authorization Act allowing DoD to restrict unclassified data with military or space applications. That authority was granted because of concern that the Freedom of Information Act might allow the Soviet Union access to sensitive research results, because data released under the Freedom of Information Act cannot be controlled by export regulations.

Benson's announcement clears up much of the confusion that has been rife since DoD enacted export-controlled sessions at an April meeting of the Society of PhotoOptical Instrumentation Engineers in Virginia. Then, it was unclear whether such sessions would become commonplace, but at at a recent private meeting, organized by the Institute of Electrical and Electronic Engineers DoD apparently declared itself happy with the formula. It remains to be seen whether learned societies will be happy to accept export-controlled sessions as a matter of course.

The new policy is a further development in the administration's continuing efforts to restrict access to sensitive technology. Benson said that reliance on security classification would be expensive and cumbersome but that export-controlled sessions would be more predictable and flexible, while allowing maximum access to restricted information consistent with national security. Benson said that the new arrangements would also have the advantage of not penalizing researchers at institutions which have set their faces against classified research on-campus.

The export regulations to which DoD is appealing are themselves being revised. According to the latest draft, information resulting from research contracts which embody restraints on free publication - even non-military contracts - would require a validated export licence to be transmitted to foreign nationals.

Boyd McKelvain of General Electric Co. made a strong plea at last week's meeting for moderation in the use of export regulations. McKelvain said he was unaware of any cost/benefit analysis supporting further restriction of data flowing to friendly nations, and warned that industrial laboratory managers are concluding that they will be forced to avoid employing foreign nationals. In McKelvain's view, unilateral action by the United States to prevent access by foreign nationals to US research could backfire and lead to reprisals, causing economic damage to US industry.
Tim Beardsley 